\title{
Bevacizumab as a last-line treatment for glioblastoma following failure of radiotherapy, temozolomide and lomustine
}

\author{
KATHARINA J. WENGER ${ }^{1,2}$, MARLIES WAGNER ${ }^{1,3}$, SE-JONG YOU ${ }^{1,3}$, KEA FRANZ $^{1,4}$, \\ PATRICK N. HARTER ${ }^{1,5}$, MICHAEL C. BURGER ${ }^{1,2}$, MARTIN VOSS $^{1,2}$, MICHAEL W. RONELLENFITSCH $^{1,2}$, \\ EMMANOUIL FOKAS ${ }^{1,6}$, JOACHIM P. STEINBACH ${ }^{1,2}$ and OLIVER BÄHR ${ }^{1,2}$ \\ ${ }^{1}$ University Hospital and University Cancer Center, German Cancer Consortium (DKTK), \\ Partner Site Frankfurt/Mainz, Frankfurt and German Cancer Research Center (DKFZ), D-69120 Heidelberg; \\ ${ }^{2}$ Dr. Senckenberg Institute of Neurooncology; ${ }^{3}$ Institute of Neuroradiology; ${ }^{4}$ Department of Neurosurgery; \\ ${ }^{5}$ Edinger Institute of Neurology; ${ }^{6}$ Department of Radiotherapy and Oncology, \\ University Hospital Frankfurt, D-60528 Frankfurt, Germany
}

Received February 7, 2017; Accepted March 22, 2017

DOI: $10.3892 / \mathrm{ol} .2017 .6251$

\begin{abstract}
In previous trials, bevacizumab failed to prolong the overall survival time in newly diagnosed glioblastoma and at the first recurrence. Randomized clinical trials at the second or further recurrence following the failure of radiotherapy, temozolomide and lomustine, and retrospective analyses focusing on this specific cohort, are not yet available. A total of 62 patients with glioblastoma who received bevacizumab after the failure of standard care, including radiotherapy, temozolomide and lomustine, were retrospectively identified. Patient characteristics, previous treatment details, concomitant therapy, response based on the Response Assessment in Neuro-Oncology criteria, and progression-free survival (PFS) and overall survival (OS) times and rates were evaluated. Furthermore, the PFS and OS times and rates were analyzed for responders and non-responders. Of the patients, $54.8 \%$ $(\mathrm{n}=34)$ responded to treatment [complete response $(\mathrm{CR}) 3.2 \%$, $\mathrm{n}=2$; partial response (PR) 51.6\%, $\mathrm{n}=32$ ]. The median PFS time was 3.5 months and the median OS time was 7.5 months. The PFS rate at 6 months was $21.5 \%$ and the OS rate at 12 months was $11.5 \%$. Responders (CR or PR) experienced a superior median PFS time compared with non-responders (i.e. stable or progressive disease; 5.4 vs. 1.9 months; $\mathrm{P}<0.0001$ ) and a superior PFS rate at 6 months ( 34.9 vs. $7.1 \% ; \mathrm{P}<0.0001)$. The median OS time (8.6 vs. 6.4 months; $\mathrm{P}<0.0001)$ and $\mathrm{OS}$ rate at 12 months ( 21.3 vs. $0 \%$; $\mathrm{P}<0.0001)$ were also superior in patients who exhibited a response to bevacizumab
\end{abstract}

Correspondence to: Dr Oliver Bähr, Dr. Senckenberg Institute of Neurooncology, University Hospital Frankfurt, 2-16 Schleusenweg, D-60528 Frankfurt, Germany

E-mail: oliver.baehr@med.uni-frankfurt.de

Key words: bevacizumab, glioblastoma, third-line therapy, last-line therapy, response rate, overall survival, progression-free survival treatment. In conclusion, the objective response rate and the PFS and OS times and rates indicate that bevacizumab has activity in patients with glioblastoma following the failure of radiotherapy, temozolomide, and lomustine. A randomized trial comparing bevacizumab with best supportive care in these patients is advised.

\section{Introduction}

The prognosis of patients with glioblastoma is poor (1-3). Gross total resection, radiotherapy and more recently, alternating electric fields, improve the outcome (4-9). Chemotherapy with temozolomide improves overall survival (OS) time predominantly in patients with glioblastoma that harbor a methylated O-6-methylguanine-DNA methyltransferase (MGMT) promoter $(10,11)$. Even in these patients, tumor progression is inevitable; at first progression, median progression-free survival (PFS) and median overall survival (OS) times typically reach 2-3 and 8-9 months, respectively (12). At progression, gross total resection can be achieved again in certain patients (13). Re-irradiation is also applied when technically possible (14). Temozolomide rechallenge and lomustine chemotherapy are frequently used to treat recurrent glioblastoma $(12,15)$. Nonetheless, as demonstrated by low PFS and OS times, the efficacy of all approaches at recurrence is limited (12).

The anti-vascular endothelial growth factor-A antibody bevacizumab was approved for the treatment of patients with recurrent glioblastoma in a number of countries, including the United States (16). European authorities refused approval in the same year on the grounds of insufficient evidence for improved OS time (17). In 2014, the results of two randomized phase III trials on the use of bevacizumab with first-line treatment were published; these trials failed to show increased OS times when standard therapy was combined with bevacizumab $(18,19)$. In recurrent glioblastoma, a randomized phase II trial indicated that bevacizumab combined with lomustine improves survival rate compared with lomustine alone (20). Therefore, a phase III 
European Organization for Research and Treatment of Cancer trial (designated BELOREC) (21) was conducted to compare lomustine monotherapy with lomustine plus bevacizumab in patients with glioblastoma at first recurrence. The results were presented at the 2015 Society for Neuro-oncology annual meeting. As in the first-line trials, bevacizumab prolonged PFS time; however, OS time was not improved (21).

Besides being approved in a number of countries, bevacizumab may be reimbursed by health insurance companies in certain countries that lack approval (17). Procedures for reimbursement are heterogeneous in the EU. Whereas certain countries, including the Netherlands, refuse reimbursement in general, others, including France, have a more generous approach to access to bevacizumab for patients with glioblastoma. In Germany, reimbursement must be applied for; such applications are only promising if all treatment options (e.g. surgery and radiotherapy) and approved drugs (e.g. temozolomide and lomustine) have already been used for the specific patient. Due to the aforementioned negative study results, the reimbursement chance is likely to decrease in the future. Due to the reimbursement issue, although bevacizumab failed to prolong OS as a first-line treatment and at first recurrence after failure of radiotherapy and chemotherapy with temozolomide, crossover was a critical issue in the previously described trials (18-21). A relevant number of patients had been treated with bevacizumab in the control treatment arm.

Despite these negative trials, bevacizumab is widely used for the treatment of patients with recurrent glioblastoma. Randomized clinical trials comparing bevacizumab with best supportive care or the investigator's choice of treatment following the failure of radiotherapy, temozolomide and lomustine are lacking. To the best of our knowledge, there are also no retrospective studies on bevacizumab focusing on patients with primary glioblastoma following the failure of radiotherapy, temozolomide and lomustine. Therefore, in the present study, a database was screened for patients with primary glioblastoma who had been treated with bevacizumab for recurrent glioblastoma. The key inclusion criterion was previous treatment with radiotherapy, temozolomide and lomustine. The response rate, PFS and OS rate and time, and the influence of response on PFS and OS rate and time were evaluated.

\section{Patients and methods}

Patient selection. The database of the University Hospital Frankfurt (Frankfurt, Germany) was screened for patients with recurrent glioblastoma who were treated with bevacizumab between January 2009 and December 2016. Only patients with primary glioblastoma were included. Patients with an isocitrate dehydrogenase (IDH) 1 mutation or a previous diagnosis of a lower grade glioma were excluded. Only patients treated with radiotherapy, temozolomide and lomustine prior to the initiation of bevacizumab treatment were included, and there were no exclusion criteria. The general patient characteristics, Karnofsky performance score (KPS) at the start of bevacizumab treatment, MGMT promoter methylation status, prior treatments, number of prior recurrences and details of bevacizumab treatment were recorded. In order to evaluate response rate, magnetic resonance imaging (MRI) scans from prior to and during bevacizumab treatment were assessed, according to the Response Assessment in Neuro-Oncology (RANO) criteria (22). To estimate progression-free survival (PFS) and overall survival (OS) times, the interval from the initiation of bevacizumab treatment to the time of progression according to RANO criteria, and to the date of patient mortality from any cause, were recorded, respectively.

A number of patients from the cohort were included in previously published studies on the use of bevacizumab in recurrent glioblastoma (23-25).

Ethics and approval. The present study was performed in accordance with the ethical standards of the 1964 Declaration of Helsinki and its later amendments. All patient data were anonymized prior to statistical analysis. Ethics board approval (Ethics Committee, University Hospital, Frankfurt, Germany) was obtained for this retrospective study. No additional data was created or used aside from the retrospective evaluation of the database.

Statistical analysis. Survival analysis was performed using the Kaplan-Meier method and the log-rank test to compare the group of non-responders with the group of responders using SPSS Statistics version 20.0 (IBM Corp., Armonk, NY, USA). $\mathrm{P}<0.05$ was considered to indicate statistical significance.

\section{Results}

Patient characteristics. The recorded patient characteristics are included in Table I. The median age of the patient cohort was 53 years; approximately one-third (21/62) of the patients were female. All patients had previously been diagnosed with primary glioblastoma. A total of $54.8 \%$ of the patients exhibited an unmethylated MGMT promoter and $27.4 \%$ exhibited a methylated MGMT promoter; for the remaining $17.8 \%$, promoter methylation status was inconclusive or unknown. A total of $8.1 \%$ of the patients underwent biopsy only as the means of initial diagnosis, with no further surgical procedures, whereas $40.3 \%$ underwent $\geq 2$ resections prior to the start of bevacizumab treatment. All patients received prior radiotherapy and $45.2 \%$ had undergone at least a second course of radiotherapy prior to treatment with bevacizumab. The median number of previous chemotherapies was 2 , and according to the inclusion criteria, all patients had received prior temozolomide and lomustine chemotherapy. The median number of prior recurrences was 3 .

Concomitant treatment and response rate. The majority of patients $(59.7 \%)$ were treated with bevacizumab monotherapy, whereas $27.4 \%$ received irinotecan or lomustine in combination with bevacizumab (Table II). The response to therapy was evaluated according to RANO criteria by two experienced neuroradiologists and results are included in Table II. A total of $35.5 \%$ of the patients exhibited progressive disease at the first MRI follow-up scan, whereas $9.7 \%$ exhibited stable disease. These groups were regarded as non-responders. On the other hand, $51.6 \%$ of patients achieved partial remission and $3.2 \%$ achieved complete remission. These groups were regarded as responders; therefore, the response rate was $54.8 \%$. 
Table I. Patient characteristics and pretreatments $(n=62)$.

\begin{tabular}{|c|c|}
\hline Characteristics & Value \\
\hline \multicolumn{2}{|l|}{ General } \\
\hline Median age (range), years & $53(28-75)$ \\
\hline Female, $\%(\mathrm{n})$ & $33.9(21)$ \\
\hline \multicolumn{2}{|l|}{ Karnofsky performance score } \\
\hline Median (range), $\%$ & $80(50-100)$ \\
\hline $50-60 \%, \%(\mathrm{n})$ & $27.4(17)$ \\
\hline $70-80 \%, \%(\mathrm{n})$ & $45.2(28)$ \\
\hline $90-100 \%, \%(n)$ & $27.4(17)$ \\
\hline \multicolumn{2}{|l|}{ Neuropathology, \% (n) } \\
\hline Primary glioblastoma & $100.0(62)$ \\
\hline $\begin{array}{l}\text { Glioblastoma with } \\
\text { oligodendroglial component }\end{array}$ & $3.2(2)$ \\
\hline \multicolumn{2}{|l|}{$\begin{array}{l}\text { O-6-methylguanine-DNA } \\
\text { methyltransferase promoter status, \% (n) }\end{array}$} \\
\hline Unmethylated & $54.8(34)$ \\
\hline Methylated & $27.4(17)$ \\
\hline Inconclusive & $11.3(7)$ \\
\hline Unknown & $6.5(4)$ \\
\hline \multicolumn{2}{|l|}{ Prior surgery, $\%$ (n) } \\
\hline Biopsy only & $8.1(5)$ \\
\hline One resection & $51.6(32)$ \\
\hline Two resections & $27.4(17)$ \\
\hline More than two resections & $12.9(8)$ \\
\hline \multicolumn{2}{|l|}{ Prior radiotherapy, \% (n) } \\
\hline Prior radiotherapy & $100.0(62)$ \\
\hline One radiotherapy & $54.8(34)$ \\
\hline Two radiotherapies & $41.9(26)$ \\
\hline More than two radiotherapies & $3.2(2)$ \\
\hline \multicolumn{2}{|l|}{ Prior chemotherapy } \\
\hline Median number of chemotherapies (range) & $2(2-6)$ \\
\hline Two chemotherapies, \% (n) & $58.1(36)$ \\
\hline Three chemotherapies, \% (n) & $35.5(22)$ \\
\hline Prior temozolomide treatment, \% (n) & $100.0(62)$ \\
\hline Prior lomustine treatment, \% (n) & $100.0(62)$ \\
\hline \multicolumn{2}{|l|}{ Prior recurrences } \\
\hline Median number of recurrences (range) & $3(2-5)$ \\
\hline Two recurrences, $\%(\mathrm{n})$ & $37.1(23)$ \\
\hline Three recurrences, $\%(\mathrm{n})$ & $38.7(24)$ \\
\hline Four recurrences, $\%(\mathrm{n})$ & $16.1(10)$ \\
\hline
\end{tabular}

Survival. PFS and OS times for the cohort are shown in Fig. 1. The median PFS time was 3.5 months (Fig. 1A) and the median OS time was 7.5 months (Fig. 1B). PFS rate at 6 months was $21.5 \%$, while OS rate at 12 months was $11.5 \%$. The median PFS time was 5.4 months for responders (Fig. 2A) compared with 1.9 months in non-responding patients (Fig. 2B; $\mathrm{P}<0.0001$ ). The PFS rate at 6 months was also superior in responders $(34.9 \%)$ compared to non-responders $(7.1 \%$; $\mathrm{P}<0.0001)$. The median OS time in responders was 8.6 months, whereas non-responders only reached a median of 6.4 months
Table II. Concomitant treatment and response $(n=62)$.

\begin{tabular}{lc}
\hline Characteristic & $\%(\mathrm{n})$ \\
\hline Concomitant therapy & \\
Bevacizumab monotherapy & $59.7(37)$ \\
Irinotecan & $16.1(10)$ \\
Lomustin & $11.3(7)$ \\
Radiotherapy & $6.5(4)$ \\
Other & $6.5(4)$ \\
Response & \\
Progressive disease & $35.5(22)$ \\
Stable disease & $9.7(6)$ \\
Partial remission & $51.6(32)$ \\
Complete remission & $3.2(2)$ \\
\hline
\end{tabular}

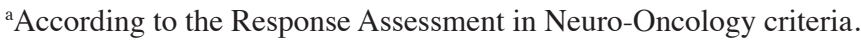
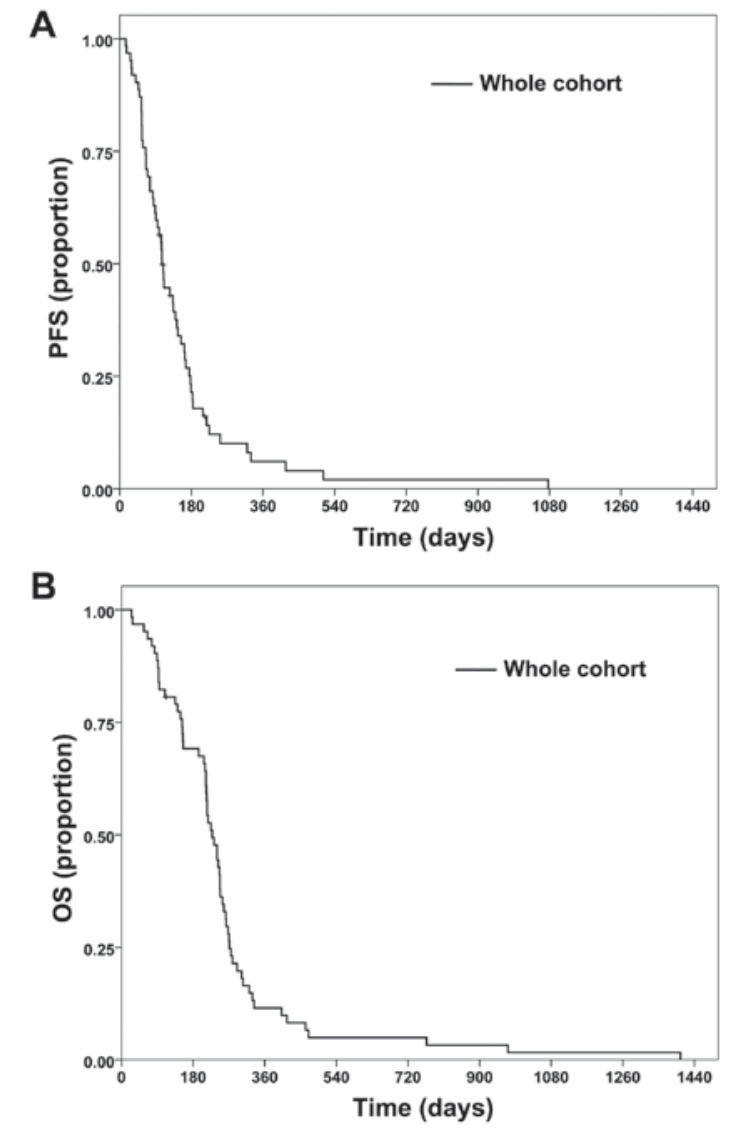

Figure 1. PFS and OS rate of the whole cohort. (A) PFS and (B) OS rate of the whole cohort. Tick marks indicate censored patients. Median PFS time was 3.5 months and PFS rate at 6 months was $21.5 \%$. Median OS time was 7.5 months and OS rate at 12 months was $11.5 \%$. PFS, progression-free survival; OS, overall survival.

$(\mathrm{P}<0.0001)$. OS rate at 12 months was $21.3 \%$ for responders and $0 \%$ for non-responders $(\mathrm{P}<0.0001)$.

MGMT promoter methylation status and patient age had no significant association with OS time and rate (data not shown). By contrast, patients with a KPS of 50 or $60 \%$ exhibited 

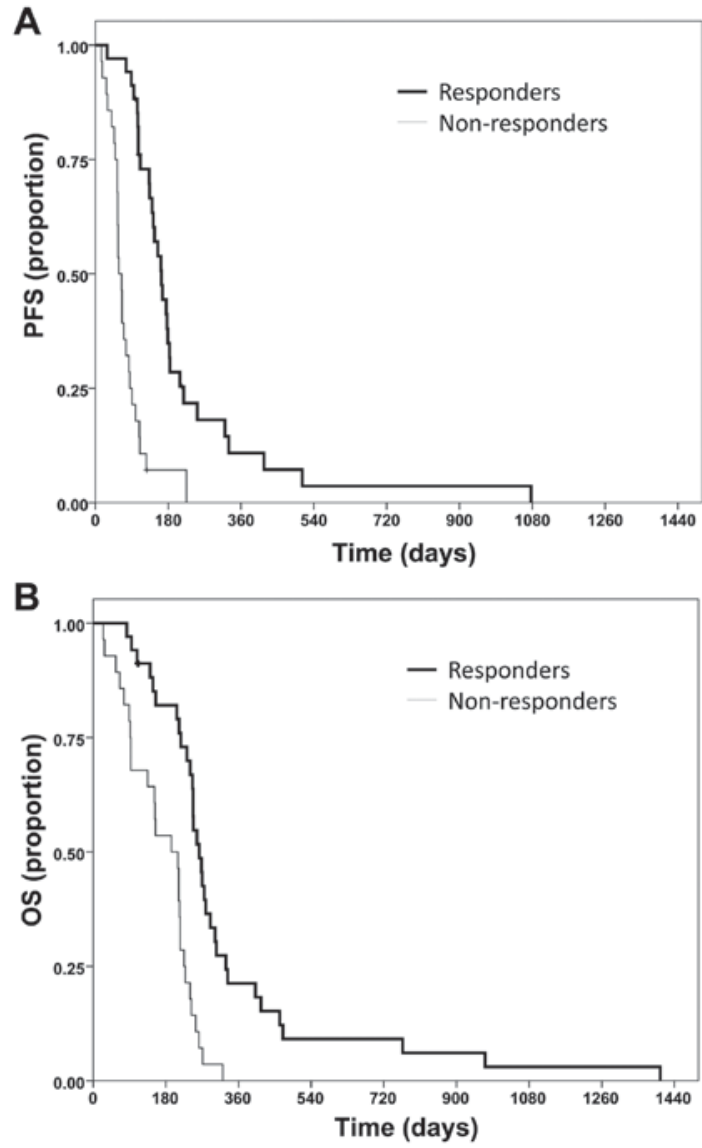

Figure 2. PFS and OS rate of responders and non-responders. Responders were defined as those with partial or complete remission; non-responders were defined as those with stable or progressive disease. Tick marks indicate censored patients. (A) PFS rate of responders (bold line) and non-responders (thin line). Median PFS time was 5.3 months for responders and 1.9 months for non-responders $(\mathrm{P}<0.0001)$. PFS rate at 6 months was $34.9 \%$ (responders) and $7.1 \%$ (non-responders). (B) OS rate of responders (bold line) and non-responders (thin line). Median OS time was 8.6 months for responders and 6.4 months for non-responders $(\mathrm{P}<0.0001)$. OS rate at 12 months was $21.3 \%$ (responders) and $0 \%$ (non-responders). PFS, progression-free survival; OS, overall survival.

a decreased median OS time (4.4 months) compared with patients with a score of 70 or $80 \%$ (8.0 months) and patients with a score of 90 or $100 \%$ ( 8.2 months) (data not shown).

\section{Discussion}

Bevacizumab has failed to prolong OS time when combined with radiotherapy and temozolomide chemotherapy as a first-line treatment, and at first recurrence when combined with lomustine $(18-21,26)$. Randomized clinical trials at second or further recurrences following the failure of radiotherapy, temozolomide and lomustine are lacking. To the best of our knowledge, the present study provides the first retrospective data for patients with primary glioblastoma treated with bevacizumab following the failure of radiotherapy, temozolomide and lomustine. In contrast to previous retrospective studies, patients with lower grade gliomas or secondary glioblastoma were not included. Moreover, previous retrospective and prospective studies have included patients at the first, second or further recurrence, with patients at the first recurrence usually being the largest group of patients (16,27-34). The present study only evaluated patients who had received radiotherapy, temozolomide and lomustine prior to bevacizumab treatment. The majority of patients had undergone first-line treatment according to the Stupp protocol (1) and had received lomustine at the first progression prior to treatment with bevacizumab at the second progression. Consequently, the median number of prior chemotherapies in the cohort was 2. Patients with $>2$ chemotherapies usually received another course of temozolomide. In addition, $>40 \%$ of the patients received a second radiotherapy; the median number of recurrences prior to bevacizumab treatment was 3 . In summary, bevacizumab usually was the last line of therapy for the patients in the cohort of the present study.

Overall, $>50 \%$ of patients in the cohort responded to bevacizumab treatment, with $51.6 \%(n=32)$ exhibiting partial remission and $3.2 \%(n=2)$ complete remission, according to RANO criteria. These values match or exceed the response rates from trials that predominantly enrolled patients at first recurrence $(16,21,22,27-34)$. In line with several previous studies, this suggests that response rates do not decrease when bevacizumab is used at later progression $(16,21,22,27-34)$.

The median PFS time of 3.5 months that was identified in the present study is in the range of previous study results. In the 'BRAIN' trial, median PFS time was 4.2 months for bevacizumab monotherapy and 5.6 months for the combination with irinotecan (16). The BELOREC trial demonstrated a median PFS time of 1.54 months for lomustine and 4.17 months for lomustine plus bevacizumab (21). Other trials, which featured a lomustine monotherapy arm at the first recurrence, exhibited a median PFS time of 1.6 and 2.7 months $(35,36)$. Together with a PFS rate at 6 months of $21.5 \%$, this suggests that bevacizumab is associated with a favorable PFS outcome in patients even subsequent to the failure of radiotherapy, temozolomide and lomustine.

Median OS time in the present study was 7.5 months. In the BELOREC trial, a time of 9.1 months was reported following treatment at first recurrence for the lomustine plus bevacizumab arm, and 8.6 months for the lomustine arm (21). Other trials reported a median OS of 8-9 months for patients treated at the first recurrence $(16,20)$. Bearing in mind that the patients of the present study were treated with bevacizumab at a median of the third recurrence and that bevacizumab was typically the last-line therapy, this suggests that bevacizumab positively influenced the OS outcome.

Response rates for bevacizumab treatment have been challenged since response may only reflect the influence of bevacizumab on the contrast enhancement and edema without actually affecting tumor growth (37). Therefore, the present study also evaluated how the response to bevacizumab was associated with PFS and OS time. Responders exhibited a median PFS time of 5.4 months compared with 1.9 months in non-responders. The median OS time in responders was 8.6 months, whereas non-responders reached 6.4 months. OS rate at 12 months was $21.3 \%$ for responders and $0 \%$ for non-responders. This association between response and PFS and OS rates and times suggests that radiological response may be a surrogate marker for survival.

One explanation for this association is that bevacizumab exhibits antitumor activity. This would fit with our clinical 
impression that certain patients benefit from treatment with bevacizumab. A detailed gene expression analysis of the cohort from the AVAGlio study corroborates this impression; patients with an IDH1 wild-type proneural glioblastoma exhibited an increase in OS of 4.3 months (38). Our previous studies in a relevant number of patients with glioblastoma identified radiological biomarkers suggesting that bevacizumab may exhibit antitumor activity $(23,24)$. In the first of these studies, $\sim 60 \%$ of bevacizumab treated patients developed tumor calcifications; survival statistics were superior for these patients (23). In the second study, $28 \%$ of the patients treated with bevacizumab developed MRI lesions that were T1 hyperintense and exhibited restricted diffusion. These patients exhibited superior median OS times (13 vs. 6.6 months) and histological analysis of these lesions revealed extensive calcified necrosis with no viable tumor cells (24). Alternately, the influence of bevacizumab on OS time could be conferred by the reduction of edema or the incidental treatment of radiation necrosis. The latter may be unlikely in the present study, as patients were significantly pre-treated, and the time from initial radiotherapy was, in general, $>6$ months.

The combination of bevacizumab with re-irradiation is another promising concept for the therapy of glioblastoma. This may not only reduce the risk of pseudoprogression, but also enhance the efficacy of re-irradiation due to the initially improved perfusion and oxygenation of the tumor. Prospective, randomized and controlled trials to consider this combination are missing. Schnell et al (39) recently reported on promising results for this combination in a large retrospective cohort: Patients that received re-irradiation and bevacizumab showed a median OS of 13.1 months. The results were further corroborated by a retrospective Italian study (40). Median OS was 11 months for patient that received re-irradiation with bevacizumab and 8.3 months for patients that received re-irradiation with fotemustin.

Due to the retrospective design of the present study and the limited number of patients, the results should be interpreted cautiously. A comprehensive evaluation of quality of life and neurocognitive function in the patient cohort was not considered; this is of particular importance, since the clinical situation of numerous patients can improve due to resolving edema and mass effect, and reducing steroid intake. It is also unclear whether bevacizumab may have adverse effects on neurocognitive function $(18,41)$. The more general side effects of bevacizumab are of comparably minor relevance in these heavily pretreated patients without further treatment options.

None of the patients of the cohort from the present study were suitable for another resection or further radiotherapy; $45.2 \%$ had already undergone radiotherapy twice. In the EU, temozolomide and nitrosourea (lomustine) are the only drugs approved for the treatment of glioblastoma. Besides bevacizumab, no other therapeutic option was available for the patients. Thus, the response rate and the PFS and OS times and rates are promising for this heavily pre-treated cohort receiving bevacizumab as last-line therapy subsequent to the failure of all approved options. Together with the association of response with superior survival time and rate, the results indicate that bevacizumab may exhibit activity in glioblastoma as a last-line treatment. It is proposed that these results justify the reimbursement of bevacizumab in these heavily pretreated patients.
Considering the negative results from first-line trials and trials at first recurrence together with the results of the present retrospective study, a randomized trial comparing bevacizumab with precisely defined best supportive care $(42,43)$, or investigator's choice of therapy, is advised.

\section{Acknowledgements}

The Dr Senckenberg Institute of Neurooncology is supported by the Dr Senckenberg Foundation. The authors wish to disclose the following conflicts of interest: Dr Oliver Bähr has served as a consultant for Roche Pharma AG (GrenzachWhylen, Germany) and has received a travel grant from Roche Pharma AG, the European distributor of bevacizumab (as Avastin); and Dr Joachim P. Steinbach has served as a consultant for Roche Pharma AG.

\section{References}

1. Stupp R, Mason WP, van den Bent MJ, Weller M, Fisher B, Taphoorn MJ, Belanger K, Brandes AA, Marosi C, Bogdahn U, et al: Radiotherapy plus concomitant and adjuvant temozolomide for glioblastoma. N Engl J Med 352: 987-996, 2005.

2. Weller M, van den Bent M, Hopkins K, Tonn JC, Stupp R, Falini A, Cohen-Jonathan-Moyal E, Frappaz D, Henriksson R, Balana C, et al: EANO guideline for the diagnosis and treatment of anaplastic gliomas and glioblastoma. Lancet Oncol 15: e395-e 403, 2014.

3. Wirsching HG, Galanis E and Weller M: Glioblastoma. Handb Clin Neurol 134: 381-397, 2016.

4. Keime-Guibert F, Chinot O, Taillandier L, Cartalat-Carel S, Frenay M, Kantor G, Guillamo JS, Jadaud E, Colin P, Bondiau PY, et al: Radiotherapy for glioblastoma in the elderly. N Engl J Med 356: 1527-1535, 2007.

5. Kreth FW, Thon N, Simon M, Westphal M, Schackert G, Nikkhah G, Hentschel B, Reifenberger G, Pietsch T, Weller M, et al: Gross total but not incomplete resection of glioblastoma prolongs survival in the era of radiochemotherapy. Ann Oncol 24: 3117-3123, 2013.

6. Laperriere N, Zuraw L and Cairncross G; Cancer Care Ontario Practice Guidelines Initiative Neuro-Oncology Disease Site Group: Radiotherapy for newly diagnosed malignant glioma in adults: A systematic review. Radiother Oncol 64: 259-273, 2002.

7. Senft C, Bink A, Franz K, Vatter H, Gasser T and Seifert V: Intraoperative MRI guidance and extent of resection in glioma surgery: A randomised, controlled trial. Lancet Oncol 12: 997-1003, 2011.

8. Stummer W, Pichlmeier U, Meinel T, Wiestler OD, Zanella F and Reulen HJ; ALA-Glioma Study Group: Fluorescence-guided surgery with 5-aminolevulinic acid for resection of malignant glioma: A randomised controlled multicentre phase III trial. Lancet Oncol 7: 392-401, 2006.

9. Vuorinen V, Hinkka S, Färkkilä M and Jääskeläinen J: Debulking or biopsy of malignant glioma in elderly people-a randomised study. Acta Neurochir (Wien) 145: 5-10, 2003.

10. Stupp R, Hegi ME, Mason WP, van den Bent MJ, Taphoorn MJ, Janzer RC, Ludwin SK, Allgeier A, Fisher B, Belanger K, et al: Effects of radiotherapy with concomitant and adjuvant temozolomide versus radiotherapy alone on survival in glioblastoma in a randomised phase III study: 5-year analysis of the EORTC-NCIC trial. Lancet Oncol 10: 459-466, 2009.

11. Hegi ME, Diserens AC, Gorlia T, Hamou MF, de Tribolet N, Weller M, Kros JM, Hainfellner JA, Mason W, Mariani L, et al: MGMT gene silencing and benefit from temozolomide in glioblastoma. N Engl J Med 352: 997-1003, 2005.

12. Seystahl K, Wick W and Weller M: Therapeutic options in recurrent glioblastoma-An update. Crit Rev Oncol Hematol 99: 389-408, 2016.

13. Montemurro N, Perrini P, Blanco MO and Vannozzi R: Second surgery for recurrent glioblastoma: A concise overview of the current literature. Clin Neurol Neurosurg 142: 60-64, 2016.

14. Nieder C, Andratschke NH and Grosu AL: Re-irradiation for recurrent primary brain tumors. Anticancer Res 36: 4985-4995, 2016. 
15. Brandes AA, Bartolotti M, Tosoni A and Franceschi E: Nitrosoureas in the management of malignant gliomas. Curr Neurol Neurosci Rep 16: 13, 2016.

16. Friedman HS, Prados MD, Wen PY, Mikkelsen T, Schiff D, Abrey LE, Yung WKA, Paleologos N, Nicholas MK, Jensen R, et al: Bevacizumab alone and in combination with irinotecan in recurrent glioblastoma. J Clin Oncol 27: 4733-4740, 2009.

17. Wick W, Weller M, van den Bent M and Stupp R: Bevacizumab and recurrent malignant gliomas: A European perspective. J Clin Oncol 28: e188-e192, 2010.

18. Gilbert MR, Dignam JJ, Armstrong TS, Wefel JS, Blumenthal DT, Vogelbaum MA, Colman H, Chakravarti A, Pugh S, Won $\mathrm{M}$, et al: A randomized trial of bevacizumab for newly diagnosed glioblastoma. N Engl J Med 370: 699-708, 2014.

19. Chinot OL, Wick W, Mason W, Henriksson R, Saran F, Nishikawa R, Carpentier AF, Hoang-Xuan K, Kavan P, Cernea $\mathrm{D}$, et al: Bevacizumab plus radiotherapy-temozolomide for newly diagnosed glioblastoma. N Engl J Med 370: 709-722, 2014.

20. Taal W, Oosterkamp HM, Walenkamp AM, Dubbink HJ, Beerepoot LV, Hanse MC, Buter J, Honkoop AH, Boerman D, de Vos FY, et al: Single-agent bevacizumab or lomustine versus a combination of bevacizumab plus lomustine in patients with recurrent glioblastoma (BELOB trial): A randomised controlled phase 2 trial. Lancet Oncol 15: 943-953, 2014.

21. Wick W, Brandes A, Gorlia T, Bendszus M, Sahm F, Taal W, Taphoorn M, Domont J, Idbaih A, Campone M, et al: Lb-05 phase iii trial exploring the combination of bevacizumab and lomustine in patients with first recurrence of a glioblastoma: The eortc 26101 trial. Neuro Oncol 17 (Suppl 5): v1, 2015.

22. Wen PY, Macdonald DR, Reardon DA, Cloughesy TF, Sorensen AG, Galanis E, Degroot J, Wick W, Gilbert MR, Lassman $\mathrm{AB}$, et al: Updated response assessment criteria for high-grade gliomas: Response assessment in neuro-oncology working group. J Clin Oncol 28: 1963-1972, 2010.

23. Bähr O, Hattingen E, Rieger J and Steinbach JP: Bevacizumab-induced tumor calcifications as a surrogate marker of outcome in patients with glioblastoma. Neuro Oncol 13: 1020-1029, 2011 .

24. Bähr O, Harter PN, Weise LM, You SJ, Mittelbronn M, Ronellenfitsch MW, Rieger J, Steinbach JP and Hattingen E: Sustained focal antitumor activity of bevacizumab in recurrent glioblastoma. Neurology 83: 227-234, 2014.

25. Schaub C, Tichy J, Schäfer N, Franz K, Mack F, Mittelbronn M, Kebir S, Thiepold AL, Waha A, Filmann N, et al: Prognostic factors in recurrent glioblastoma patients treated with bevacizumab. J Neurooncol 129: 93-100, 2016.

26. Herrlinger U, Schäfer N, Steinbach JP, Weyerbrock A, Hau P, Goldbrunner R, Friedrich F, Rohde V, Ringel F, Schlegel U, et al: Bevacizumab plus irinotecan versus temozolomide in newly diagnosed O6-methylguanine-DNA methyltransferase nonmethylated glioblastoma: The randomized GLARIUS trial. J Clin Oncol 34: 1611-1619, 2016.

27. Chamberlain MC and Johnston SK: Salvage therapy with single agent bevacizumab for recurrent glioblastoma. J Neurooncol 96 : 259-269, 2010

28. Kreisl TN, Kim L, Moore K, Duic P, Royce C, Stroud I, Garren N, Mackey M, Butman JA, Camphausen K, et al: Phase II trial of single-agent bevacizumab followed by bevacizumab plus irinotecan at tumor progression in recurrent glioblastoma. J Clin Oncol 27: 740-745, 2009.

29. Møller S, Grunnet K, Hansen S, Schultz H, Holmberg M, Sorensen M, Poulsen HS and Lassen U: A phase II trial with bevacizumab and irinotecan for patients with primary brain tumors and progression after standard therapy. Acta Oncol 51: 797-804, 2012
30. Nagane M, Nishikawa R, Narita Y, Kobayashi H, Takano S, Shinoura N, Aoki T, Sugiyama K, Kuratsu J, Muragaki Y, et al: Phase II study of single-agent bevacizumab in Japanese patients with recurrent malignant glioma. Jpn J Clin Oncol 42: 887-895, 2012.

31. Raizer JJ, Grimm S, Chamberlain MC, Nicholas MK, Chandler JP, Muro K, Dubner S, Rademaker AW, Renfrow J and Bredel M: A phase 2 trial of single-agent bevacizumab given in an every-3-week schedule for patients with recurrent high-grade gliomas. Cancer 116: 5297-5305, 2010.

32. Vredenburgh JJ, Desjardins A, Herndon JE II, Dowell JM, Reardon DA, Quinn JA, Rich JN, Sathornsumetee S, Gururangan S, Wagner $\mathrm{M}$, et al: Phase II trial of bevacizumab and irinotecan in recurrent malignant glioma. Clin Cancer Res 13: 1253-1259, 2007

33. Vredenburgh JJ, Desjardins A, Herndon JE II, Marcello J, Reardon DA, Quinn JA, Rich JN, Sathornsumetee S, Gururangan S, Sampson J, et al: Bevacizumab plus irinotecan in recurrent glioblastoma multiforme. J Clin Oncol 25: 4722-4729, 2007.

34. Zuniga RM, Torcuator R, Jain R, Anderson J, Doyle T, Ellika S, Schultz L and Mikkelsen T: Efficacy, safety and patterns of response and recurrence in patients with recurrent high-grade gliomas treated with bevacizumab plus irinotecan. J Neurooncol 91: 329-336, 2009.

35. Wick W, Puduvalli VK, Chamberlain MC, van den Bent MJ, Carpentier AF, Cher LM, Mason W, Weller M, Hong S, Musib L, et al: Phase III study of enzastaurin compared with lomustine in the treatment of recurrent intracranial glioblastoma. J Clin Oncol 28: 1168-1174, 2010.

36. Batchelor TT, Mulholland P, Neyns B, Nabors LB, Campone M, Wick A, Mason W, Mikkelsen T, Phuphanich S, Ashby LS, et al: Phase III randomized trial comparing the efficacy of cediranib as monotherapy, and in combination with lomustine, versus lomustine alone in patients with recurrent glioblastoma. J Clin Oncol 31: 3212-3218, 2013

37. Hattingen E, Jurcoane A, Daneshvar K, Pilatus U, Mittelbronn M, Steinbach JP and Bähr O: Quantitative T2 mapping of recurrent glioblastoma under bevacizumab improves monitoring for non-enhancing tumor progression and predicts overall survival. Neuro Oncol 15: 1395-1404, 2013.

38. Sandmann T, Bourgon R, Garcia J, Li C, Cloughesy T, Chinot OL, Wick W, Nishikawa R, Mason W, Henriksson R, et al: Patients with proneural glioblastoma may derive overall survival benefit from the addition of bevacizumab to first-line radiotherapy and temozolomide: Retrospective analysis of the AVAglio trial. J Clin Oncol 33: 2735-2744, 2015.

39. Schnell O, Thorsteinsdottir J, Fleischmann DF, Lenski M, Abenhardt W, Giese A, Tonn JC, Belka C, Kreth FW and Niyazi M: Re-irradiation strategies in combination with bevacizumab for recurrent malignant glioma. J Neurooncol 130: 591-599, 2016.

40. Minniti G, Agolli L, Falco T, Scaringi C, Lanzetta G, Caporello P, Osti MF, Esposito V and Enrici RM: Hypofractionated stereotactic radiotherapy in combination with bevacizumab or fotemustine for patients with progressive malignant gliomas. J Neurooncol 122: 559-566, 2015.

41. Fathpour P, Obad N, Espedal H, Stieber D, Keunen O, Sakariassen PØ, Niclou SP and Bjerkvig R: Bevacizumab treatment for human glioblastoma. Can it induce cognitive impairment? Neuro Oncol 16: 754-756, 2014.

42. Zafar SY, Currow DC, Cherny N, Strasser F, Fowler R and Abernethy AP: Consensus-based standards for best supportive care in clinical trials in advanced cancer. Lancet Oncol 13: e77-e82, 2012.

43. Zafar SY, Currow D and Abernethy AP: Defining best supportive care. J Clin Oncol 26: 5139-5140, 2008. 